\title{
Intravesical Prostatic Projection: A Good Predictor of Outcome of Trial without Catheter in Patients with Acute Urinary Retention Due to Benign Prostatic Hyperplasia \\ Amarendra Nath Sarkar ${ }^{1}$, Partha Pratim Deb ${ }^{2 *}$, Ranjit Kumar Das ${ }^{3}$
}

${ }^{1}$ Associate Professor, Department of General Surgery, North Bengal Medical College, Darjeeling, India

${ }^{2}$ Ex MCh Trainee, Department of Urology, R G Kar Medical College, Kolkata, India

${ }^{3}$ Ex Professor and HOD, Department of Urology, R G Kar Medical College, Kolkata, India

DOI: $10.36347 /$ sjams.2020.v08i05.035

| Received: 10.05.2020 | Accepted: 22.05.2020 | Published: 28.05.2020

*Corresponding author: Partha Pratim Deb

Abstract

Acute urinary retention (AUR) is a urological emergency and can affect about 5-25 per 1000 person years. It accounts for one third of patients requiring surgery for benign prostatic hyperplasia (BPH). The initial management of AUR is per urethral catheterization for bladder decompression following which patients are advised alpha blocker and called for trial of voiding without catheter at a later date. If the trial without catheter (TWOC) fails, one may need surgical intervention. The objective of our study was to assess whether the grade of intravesical prostatic projection (IPP) can predict the outcome of TWOC following an episode of AUR. A total of ninety patients coming to our outdoor in a study period of one year were included. It was observed that the failure rate of TWOC of grade III IPP was significantly higher compared to grade I and grade II but age and prostate volume had no significant impact on the outcome of TWOC in these patients. We conclude that IPP is a strong predictor of the outcome of TWOC in patients with AUR due to BPH.

Keywords: Acute urinary retention, benign prostatic hyperplasia, trial without catheter, intravesical prostatic projection, grade.

Copyright @ 2020: This is an open-access article distributed under the terms of the Creative Commons Attribution license which permits unrestricted use, distribution, and reproduction in any medium for non-commercial use (NonCommercial, or CC-BY-NC) provided the original author and source are credited.

\section{INTRODUCTION}

Acute urinary retention (AUR) secondary to benign prostatic hyperplasia $(\mathrm{BPH})$ is a urological emergency characterized by inability to pass urine which is of sudden onset and is associated with pain. The frequency of this complication is about 5-25 per 1000 person-years. AUR accounts for one third of the patients undergoing surgery for BPH [1].

The management of AUR is the immediate urethral catheterization. If per urethral catheterization fails then suprapubic catheterization is the next step. In the past, early surgery was the first approach and it was safer also as it could avoid an indwelling catheterization [2]. Long-term catheterization (either per urethral or suprapubic) was the second approach with the disadvantages associated with it. The third approach was the trial without catheter (TWOC) with medication in the form of alpha blocker. It was associated with reasonably good success rate. The patients who had a successful TWOC were followed with either medical therapy or TURP. Those patients who failed TWOC were recatheterized and reassessed for the future treatment options such as surgery, a second trial or long term catheterization [3].

The aim of this study is to assess whether the grade of intravesical prostatic protrusion can predict the outcome of TWOC following an episode of AUR due to $\mathrm{BPH}$.

\section{Material AND Methods}

A prospective study was conducted in the department of Urology, R G Kar medical college, Kolkata for a period of one year. At least 95 male patients with AUR secondary to clinical diagnosis of $\mathrm{BPH}$, attending the emergency department of R G Kar medical college and hospital were enrolled for the study. Detailed clinical history and examination including digital rectal examination (DRE) was performed and the results were recorded by the use of a predesigned form. Ultrasonography (USG) of the KUB and prostate was done after relief of retention. Written informed consent was taken from all the patients. Patients were discharged from the emergency department after catheterization with the advice to take 
tamsulosin- $0.4 \mathrm{mg}$ OD and to return to the urology OPD for TWOC after 3 days. TWOC was performed in the hospital and was considered successful if the patient voids within 6 hours of catheter removal with a maximum flow rate $>5 \mathrm{ml} / \mathrm{sec}$ and postvoid residual volume $<200 \mathrm{~mL}$ on the basis of currently prevalent criteria in the literature. Those failing to void were managed by recatheterization and leveled as failed TWOC.

Statistical analysis was performed with the available version of standard statistical software SPSS version 20. Logistic regression analysis was used for identifying predictors of outcome of TWOC and other tests like Chi square test was used to compare the outcome of factors like bladder wall thickness, IPP and prostate volume by USG. Odd's ratio was calculated to compare the outcome of TWOC in patients with different grades of IPP.

\section{RESUltS}

Among the 95 patients assessed with ultrasound following catheterization, 90 patients turned up for trial without catheter. The age of the patients in the study ranged from a minimum of 46 years to a maximum of 95 years. The mean age of the patients was 65.16 years and the median age of them was 65 years. The mean age of the patients in the successful group was 65.41 years (95\% CI, range 63.4-67.4) and that in the failure group was 64.82 years $(95 \% \mathrm{CI}$, range 61.5 68.1 ) as depicted in Table-1.

Table 1: Descriptive demographic profile of the patients in years

\begin{tabular}{|c|c|c|c|c|c|}
\hline \multirow{2}{*}{ Age } & \multicolumn{3}{|c|}{ TWOC result } & \multirow{2}{*}{$\begin{array}{r}\text { Statistic } \\
65.41\end{array}$} & \multirow{2}{*}{$\begin{array}{r}\text { Std. Error } \\
.999\end{array}$} \\
\hline & \multirow[t]{11}{*}{ success } & \multicolumn{2}{|l|}{ Mean } & & \\
\hline & & \multirow[t]{2}{*}{ 95\% Confidence Interval for Mean } & Lower Bound & 63.41 & \\
\hline & & & Upper Bound & 67.42 & \\
\hline & & \multicolumn{2}{|l|}{$5 \%$ Trimmed Mean } & 65.46 & \\
\hline & & \multicolumn{2}{|l|}{ Median } & 65.00 & \\
\hline & & \multicolumn{2}{|l|}{ Variance } & 50.887 & \\
\hline & & \multicolumn{2}{|l|}{ Std. Deviation } & 7.134 & \\
\hline & & \multicolumn{2}{|l|}{ Minimum } & 46 & \\
\hline & & \multicolumn{2}{|l|}{ Maximum } & 80 & \\
\hline & & \multicolumn{2}{|l|}{ Range } & 34 & \\
\hline & & \multicolumn{2}{|l|}{ Interquartile Range } & 10 & \\
\hline & \multirow[t]{11}{*}{ failure } & \multicolumn{2}{|l|}{ Mean } & 64.82 & 1.630 \\
\hline & & \multirow[t]{2}{*}{$95 \%$ Confidence Interval for Mean } & Lower Bound & 61.52 & \\
\hline & & & Upper Bound & 68.12 & \\
\hline & & \multicolumn{2}{|l|}{$5 \%$ Trimmed Mean } & 64.32 & \\
\hline & & \multicolumn{2}{|l|}{ Median } & 61.00 & \\
\hline & & \multicolumn{2}{|l|}{ Variance } & 103.572 & \\
\hline & & \multicolumn{2}{|l|}{ Std. Deviation } & 10.177 & \\
\hline & & \multicolumn{2}{|l|}{ Minimum } & 50 & \\
\hline & & \multicolumn{2}{|l|}{ Maximum } & 95 & \\
\hline & & \multicolumn{2}{|l|}{ Range } & 45 & \\
\hline & & \multicolumn{2}{|l|}{ Interquartile Range } & 15 & \\
\hline
\end{tabular}

The prostate volume was measured by taking all the parameters on ultrasound and analysing by the formula (height $\mathrm{X}$ width $\mathrm{X}$ anteroposterior diameter $\mathrm{X}$ 0.52 ). The mean prostate volume in the successful group was $56.8 \mathrm{ml}(95 \% \mathrm{CI}$, range 51.9-61.8) and the same for the failure group was $61.4 \mathrm{ml}(95 \% \mathrm{CI}$, range 57-65.8) as shown in Table- 2. 
Table-2: showing statistics of prostatic volume in milliliters on USG

\begin{tabular}{|c|c|c|c|c|c|}
\hline \multirow{3}{*}{$\begin{array}{l}\text { USG(prostate } \\
\text { volume) }\end{array}$} & \multicolumn{3}{|c|}{ TWOC result } & \multirow{2}{*}{$\begin{array}{l}\text { Statistic } \\
56.88 \\
\end{array}$} & \multirow{2}{*}{$\begin{array}{l}\text { Std. Error } \\
2.450 \\
\end{array}$} \\
\hline & \multirow[t]{11}{*}{ Success } & \multicolumn{2}{|l|}{ Mean } & & \\
\hline & & \multirow{2}{*}{$\begin{array}{l}95 \% \text { Confidence } \\
\text { Interval for Mean }\end{array}$} & Lower Bound & 51.96 & \\
\hline & & & Upper Bound & 61.80 & \\
\hline & & \multicolumn{2}{|l|}{ 5\% Trimmed Mean } & 56.28 & \\
\hline & & \multicolumn{2}{|l|}{ Median } & 58.00 & \\
\hline & & \multicolumn{2}{|l|}{ Variance } & 306.066 & \\
\hline & & \multicolumn{2}{|l|}{ Std. Deviation } & 17.495 & \\
\hline & & \multicolumn{2}{|l|}{ Minimum } & 26 & \\
\hline & & \multicolumn{2}{|l|}{ Maximum } & 105 & \\
\hline & & \multicolumn{2}{|l|}{ Range } & 79 & \\
\hline & & \multicolumn{2}{|l|}{ Interquartile Range } & 19 & \\
\hline & \multirow[t]{11}{*}{ Failure } & \multicolumn{2}{|l|}{ Mean } & 61.46 & 2.167 \\
\hline & & \multirow{2}{*}{$\begin{array}{l}95 \% \quad \text { Confidence } \\
\text { Interval for Mean }\end{array}$} & Lower Bound & 57.07 & \\
\hline & & & Upper Bound & 65.85 & \\
\hline & & \multicolumn{2}{|l|}{ 5\% Trimmed Mean } & 60.65 & \\
\hline & & \multicolumn{2}{|l|}{ Median } & 59.00 & \\
\hline & & \multicolumn{2}{|l|}{ Variance } & 183.202 & \\
\hline & & \multicolumn{2}{|l|}{ Std. Deviation } & 13.535 & \\
\hline & & \multicolumn{2}{|l|}{ Minimum } & 40 & \\
\hline & & \multicolumn{2}{|l|}{ Maximum } & 100 & \\
\hline & & \multirow{2}{*}{\multicolumn{2}{|c|}{$\begin{array}{l}\text { Range } \\
\text { Interquartile Range }\end{array}$}} & 60 & \\
\hline & & & & 19 & \\
\hline
\end{tabular}

Among the 90 patients with AUR , 33.3\% (30 out of 90) were found to have grade I, $42.2 \%$ had grade II and $24.4 \%$ had grade III intravesical prostatic protrusion (IPP). Chi square test was performed to compare the outcome of TWOC in relation to different grades of IPP and it was observed that the failure rate of TWOC was $10 \%$ (3 out of 30 ), $52.6 \%$ (20 out of 38 ) and $72.7 \%$ (16 out of 22) for grade I,II,III IPP respectively as shown in the table below. After determining the odd's ratio it was seen that failure rate of grade III was 18.9 times that of grade I and 1.13 times that of grade II .So, IPP has a significant influence on the outcome of TWOC (P value $=0.001$ ).

Table-3: Showing patients in incidence of different USG (IPP) grades

\begin{tabular}{|c|l|l|l|l|l|}
\hline \multicolumn{2}{|c|}{} & Frequency & Percent & Valid Percent & Cumulative Percent \\
\hline Grade & 1 & 30 & 33.3 & 33.3 & 33.3 \\
\cline { 2 - 6 } & 2 & 38 & 42.2 & 42.2 & 75.6 \\
\cline { 2 - 6 } & 3 & 22 & 24.4 & 24.4 & 100.0 \\
\cline { 2 - 6 } & Total & 90 & 100.0 & 100.0 & \\
\hline
\end{tabular}

Logistic regression analysis was performed to identify the predictive factors of outcome of TWOC adjusting the confounding variables and in the end it was observed that IPP was a strong predictive factor which was statistically significant $(\mathrm{P}<0.05)$. Other factors like age, prostate volume had no significant influence on the outcome of TWOC as their value are not statistically significant $(\mathrm{P}>0.05)$ as shown the table below.

Table-4: Showing the confounding variables in the Equation

\begin{tabular}{|l|l|l|l|l|l|l|}
\hline & B & df & Sig. & $\operatorname{Exp(B)}$ & \multicolumn{2}{|c|}{ 95\% C.I.for EXP(B) } \\
\cline { 5 - 8 } & & & & & Lower & Upper \\
\hline Age & -.026 & 1 & .446 & .974 & .910 & 1.042 \\
\hline USG (prostate volume) & .008 & 1 & .660 & 1.008 & .972 & 1.046 \\
\hline USGIPP & & 2 & .002 & & & \\
\hline USGIPP(1) & -2.939 & 1 & .001 & .053 & .009 & .304 \\
\hline USGIPP(2) & -.127 & 1 & .852 & .881 & .232 & 3.350 \\
\hline
\end{tabular}

\section{DISCUSSION}

Benign prostatic hyperplasia (BPH) is one of the commonest diseases encountered in urological practice. Acute urinary retention (AUR) is a serious complication of BPH. Current standard management of AUR is initial bladder catheterization for decompression. Alpha blocker medication is started at the same time which has shown to improve the success 
rate during TWOC $[4,5]$. The patient should undergo at least one TWOC before TURP is considered.

In the large Reten study, the median age of the patients was 70 years [3] compared to 65 years in our study. The patients of less than 70 years of age were associated with a successful TWOC. Alfaur study also reported that higher rate of failed TWOC in men aged $>65$ years of age [6]. Our mean age of successful TWOC patients was 65 years (61years for the failed patients). Our results are similar to the Malaysian study which concluded that age of patients had no significant influence on the outcome of TWOC [7].

In one study [8] $62.07 \%$ of the patients with prostate volume of less than $45 \mathrm{ml}$ had a successful trial and $39.29 \%$ of cases with a prostate volume more than $45 \mathrm{ml}$ had a unsuccessful trial. In another study Bhattachan [9] reported prostate size of $40 \mathrm{gm}$ on transabdominal ultrasound to predict the outcome of TWOC with a specificity of $73 \%$ and a sensitivity of $84 \%$. In our study, $49.5 \mathrm{ml}$ of prostate volume was the cut off above which there was a high chance of TWOC failure.

In our study $10 \%$ of cases of grade I, $52.6 \%$ cases of grade II and $72.7 \%$ cases of grade III IPP failed TWOC. The failure rate of grade III IPP was 18.9 times that of grade I IPP and 1.13 times that of grade II IPP. Similar result was found in other three studies, one of them revealed that a cut off of $8.2 \mathrm{~mm}$ for intravesical prostatic protrusion detected failures of TWOC with a specificity of $87 \%$ and successes with a specificity of $64 \%$ [10], another study showed that men with an IPP of $10 \mathrm{~mm}$ or less compared to those with a larger IPP were 6 times more likely to have a successful trial without catheter [11], last one revealed that grade III IPP is a strong predictor in the failure of outcome of TWOC. This finding concurs with results from other studies e.g. one done in Singapore by Foo et al., [12] who did a six months follow up in which 4 patients who initially had successful TWOC had a repeated episode of AUR. Three of these patients were of grade III IPP and one of grade II IPP. Grade III IPP was also associated with a higher BOO index than grade I and II patients with BPH.

\section{CONCLUSION}

In our experience, intravesical prostatic protrusion is a strong predictor of outcome of TWOC in patients with AUR due to BPH. Patients with high grade IPP $(>10 \mathrm{~mm})$ would very unlikely to benefit from TWOC and can be considered for immediate TURP following an episode of AUR.

\section{REFERENCES}

1. Roehrborn CG. Acute urinary retention: risks and management. Reviews in urology. 2005;7(Suppl 4):S31-41.

2. Pickard R, Emberton M, Neal DE. The management of men with acute urinary retention. National Prostatectomy Audit Steering Group. British journal of urology. 1998 May;81(5):71220.

3. Fitzpatrick JM, Desgrandchamps F, Adjali K, Guerra LG, Hong SJ, Khalid SE, Ratana- Olarn K, Reten- World Study Group. Management of acute urinary retention: a worldwide survey of 6074 men with benign prostatic hyperplasia. BJU international. 2012 Jan;109(1):88-95.

4. Claus GR. Current medical therapies for men with lower urinary tract symptoms and benign prostatic hyperplasia; achievements and limitations. Rev Urol.2008; 10(1):14-25.

5. Shanmugasundaram R, Kekre NS. Is there a better indicator for predicting the outcome of trial without catheter? Indian J Urol.2007; 23(4):485486.

6. McNeill SA, Hargreave TB; Members of the Alfaur Study Group. Alfuzosin once daily facilitates return to voiding in patients in acute urinary retention. J Urol 2004; 171:2316-20.

7. Sharis OS, Zulkifli MZ, Hamzaini AH. Predicting outcome of trial of voiding without catheter in acute urinary retention with intravesical prostatic protrusion. The Malaysian journal of medical sciences: MJMS. 2013 Jan;20(1):56-59.

8. Mahadik P, Vaddi SP, Godala CM, Reddy VV, Sambar VK. Factors affecting trial without catheter for first spontaneous acute urinary retention. International neurourology journal. 2013 Sep;17(3):121-126.

9. Bhomi KK, Bhattachan CL. Factors predicting the success of a trial without catheter in acute urinary retention secondary to benign prostatic hyperplasia. Nepal Medical College journal: NMCJ. 2011 Sep;13(3):178-81

10. Panda A, Dorairajan LN, Kumar S, Nayak P. 116: Acute urinary retention from benign prostatic hyperplasia: Factors affecting outcome of a trial without catheter. Indian Journal of Urology. 2008 Nov 2;24.

11. Mariappan P, Brown DJ, McNeill AS. Intravesical prostatic protrusion is better than prostate volume in predicting the outcome of trial without catheter in white men presenting with acute urinary retention: a prospective clinical study. The Journal of urology. 2007 Aug 1;178(2):573-7.

12. Tan YH, Foo KT. IPP predicts the outcome of trial without catheter following AUR. J urol. 2003dec; 170(6pt1):2339-41. 